\title{
Imperativos de um Tempo Presente: Ensino de História e Gênero em um projeto desenvolvido por bolsistas do Pibid
}

\section{Imperatives of a Present Time: History Teaching and Gender in a project developed by Pibid's university students}

Caroline Jaques Cubas ${ }^{\star}$

Luciana Rossato**

\section{RESUMo}

O objetivo deste artigo é problematizar as possibilidades e dificuldades de discussões ancoradas pela categoria gênero em aulas de história na Educação Básica. Para tanto, elencamos uma série de atividades produzidas e ministradas por bolsistas do Pibid cujo tema versava sobre gênero e história das mulheres. A partir dos relatos produzidos pelos bolsistas, referentes às suas experiências com turmas de $9^{\circ}$ ano, refletimos sobre os recortes de conteúdo trabalhados, sobre a receptividade e resistências das turmas no que concerne à proposta em questão e, finalmente, sobre a percepção e significados atribuídos às questões de gênero na trajetória dos próprios bolsistas de iniciação à docência. Para esta análise, nos apoiamos em debates acerca da categoria de gênero, em saberes concernentes à formação docente e no conceito de experiência.

Palavras-chave: ensino de História; gênero; formação docente.

\section{Abstract}

The aim of this article is to discuss the possibilities and difficulties of discussions anchored by gender category in history classes in Basic Education. Therefore, we list a number of activities produced and taught by Pibid's university students. These were about gender and women's history. From the reports produced by the students, referring to their experiences with 9th year classes, we reflect about the subject contents, about responsiveness and resistance of the groups regarding the proposal in question and, finally, about perception and meanings attributed to gender issues in the path of initiation to teaching fellows. For this analysis, we are supported in the discussions about gender category, about the knowledge concerning teacher training, and the concept of experience.

Keywords: History teaching; gender; teachers training.

\footnotetext{
* Doutora em História Cultural pela Universidade Federal de Santa Catarina (UFSC). Professora adjunta do Departamento de História da Universidade do Estado de Santa Catarina (Udesc). Florianópolis, SC, Brasil. caroljcubas@gmail.com

** Doutora em História pela Universidade Federal do Rio Grande do Sul (UFRGS). Professora adjunta do Departamento de História da Universidade do Estado de Santa Catarina (Udesc). Florianópolis, SC, Brasil. lucianarossato1972@gmail.com
} 


\section{Percursos E PERCALÇOS DA INICIAÇÃo À DOCÊNCIA}

A educação é um tema de confrontos e debates que envolvem e mobilizam grupos que possuem diferentes concepções sobre qual a função da escola e qual o papel do professor/a na educação das crianças e jovens. Temas polêmicos como aqueles que se referem às questões de gênero e ao controverso projeto "Escola sem partido" têm mobilizado grande parcela da sociedade brasileira. Grupos de diferentes matizes políticos e religiosos, a favor ou contra, estão envolvidos no debate e pressionam vereadores, deputados e senadores. As discussões são acirradas nas redes sociais e nas mídias, o que pode ser constatado, por exemplo, com base na grande participação na enquete eletrônica feita pelo Senado brasileiro para o Projeto de Lei no 193 de 2016 apresentado pelo senador Magno Malta, um dos projetos que teve maior participação popular. ${ }^{1} \mathrm{Ou}$ tro debate que também mobilizou a sociedade e, particularmente, os historiadores e professores de História, foi a apresentação da primeira versão sobre a Base Nacional Comum Curricular ${ }^{2}$ em 16 de setembro de 2015.

Já sobre a inserção de reflexões a respeito de gênero nas escolas, os debates acirraram-se quando da tramitação do Plano Nacional da Educação (PNE) no Congresso Nacional em 2014. Nesse documento, foi retirado do texto a parte que defendia, no que diz respeito à escola, a função de superar a desigualdade educacional, desenvolvendo atividades a fim de promover a igualdade de gênero e orientação sexual. Além das disputas no Legislativo nacional, tais contendas foram realizadas também nos Legislativos estaduais e municipais no decorrer do ano de 2015. Elas tinham por prerrogativa a manutenção ou exclusão do termo "gênero" nos seus respectivos planos estaduais e municipais de educação. É importante salientar a ativa participação das instituições religiosas nesse debate, seja por meio da representatividade da "bancada evangélica” no Legislativo, seja pelas manifestações de diferentes Igrejas (especialmente católicas e neopentecostais), que desaconselharam veementemente a manutenção das questões de gênero nos planos de educação. Tal prática pode ser facilmente constatada através de manifestações na internet, da publicação de folhetos ou mesmo de cartilhas a esse respeito. ${ }^{3}$

Tais conflitos, bastante característicos do tempo presente, remetem a determinadas concepções de mundo e de educação, as quais estão em constante disputa nas instituições escolares, nas políticas públicas, e influenciam a 
formação de professores e professoras. Nesse tumultuado contexto, o ensino escolar da história deve contribuir para que as crianças e jovens tenham acesso ao passado, não como um conjunto de informações cristalizadas, mas como uma ferramenta que os torne aptos a conhecerem os processos de produção do conhecimento histórico e as disputas e embates que ocorrem no presente.

Nesse mesmo sentido, o subprojeto de História do Pibid da Universidade do Estado de Santa Catarina tem como proposta de trabalho subsidiar e possibilitar experiências de ensino para acadêmicos e acadêmicas ainda durante o processo de formação docente. Por isso investe-se na elaboração de aulas-oficina a partir de temas que bolsistas, em conjunto com os professores/as supervisores/as, identificam como necessários para a formação dos/as estudantes. Dentre os vários temas escolhidos nos últimos semestres, destacamos, pela frequência e relevância, a proposição de oficinas sobre gênero e história das mulheres em diferentes períodos históricos. ${ }^{4}$

Tendo em vista essas questões, o objetivo deste artigo é apresentar, não apenas a descrição de atividades, dificuldades e resultados obtidos pelos alunos, mas propor uma reflexão acerca desse fundamental imperativo do tempo presente. Ao alocarmos os debates referentes às relações entre gênero e educação como imperativos de um tempo presente, destacamos o caráter indeterminado desse presente. A partir da indeterminação do presente, segundo François Dosse, "o historiador, então, recebe uma nova tarefa que é a de encontrar a indeterminação do presente das sociedades passadas. Essa nova ambição leva a uma reavaliação da contingência, da pluralidade das possibilidades, da diversidade das escolhas possíveis dos atores" (2012, p.15). Além da possibilidade de uma percepção menos fatalista a respeito do presente, essa perspectiva possibilita-nos pensar que tanto o presente (e portanto os debates por ele impostos) quanto os posicionamentos referentes às questões de gênero são construídos no tempo.

Antes, porém, de problematizar as atividades desenvolvidas pelos alunos e alunas vinculados ao Pibid, é fundamental ressaltar a importância desse programa no processo de formação docente. Aprender a ser professor vai além da apropriação dos conhecimentos da área de História e dos pressupostos pedagógicos que perpassam o ambiente universitário. Envolve a experimentação e a aquisição de experiência que somente ocorrem mediante o contato com o campo de atuação. Para Maurice Tardif (2002, p.39) os saberes docentes se dão 
a partir das "múltiplas articulações entre a prática docente e os saberes", que são os saberes da formação profissional, os saberes disciplinares, os saberes curriculares e os saberes experienciais. Esses saberes são plurais, heterogêneos, temporais, datados e situados. São saberes plurais e heterogêneos porque provêm de diversas fontes, são ecléticos e sincréticos, uma vez que, para construí-lo são utilizadas teorias, concepções e técnicas diversas, visando menos à coerência teórica e mais à eficiência nos resultados. São saberes temporais porque advêm da história de vida do professor, de que faz parte a vida escolar, e se desenvolvem durante a carreira, em seu espaço de atuação profissional, bem como nas relações estabelecidas com os colegas e a direção da escola. Como o trabalho do professor exige que sejam atendidos múltiplos objetivos, recorre-se a diferentes saberes e competências. Saberes personalizados e situados, na medida em que são apropriados, incorporados e subjetivados em função de situações específicas de trabalho (Tardif, 2000; 2002).

Com o objetivo de possibilitar aos graduandos e graduandas em cursos de licenciatura um contato efetivo entre o campo de atuação (escola) e a universidade (espaço de formação), instituiu-se o Programa Institucional de Bolsa de Iniciação à Docência (Pibid). Foi criado pela Capes, com o intuito de incentivar a formação inicial de professores para a Educação Básica, valorizar o magistério e o espaço da escola pública como um espaço de formação e de produção de conhecimento, de modo que os acadêmicos dos cursos de licenciatura entrem em contato com seu futuro local de trabalho. A primeira chamada pública do Pibid foi realizada pelo Edital MEC/Capes/FNDE de 2007 e atendeu somente às universidades federais e a Física, Química, Biologia e Matemática, áreas consideradas críticas devido à falta de professores habilitados a atender as necessidades da educação básica. Nos editais posteriores (2009, 2010, 2011, 2013) o programa foi estendido para contemplar outras áreas da Educação Básica e aberto à participação de Universidades Estaduais, Comunitárias e Institutos de Ensino Superior, além das Universidades Federais que já eram atendidas desde o primeiro edital.

No ano de 2011 a Udesc concorreu ao Edital no 001/2011/Capes do Programa de Iniciação à Docência (Pibid) - com o projeto "Práticas pedagógicas na Educação Básica: qualificando a formação inicial e continuada”. Nesse projeto, que se encerrou em 2013, estiveram envolvidos dez cursos de graduação dessa universidade e 96 graduandos bolsistas. O curso de História propôs o 
subprojeto intitulado "O pensamento histórico de crianças e adolescentes: o ensino de História na Educação Básica" no qual foram previstas dezoito bolsas para graduandos, duas bolsas para supervisores, que são professores de História alocados em regime de trabalho efetivo em Escolas de Educação Básica da cidade de Florianópolis ${ }^{5}$ (uma municipal e outra estadual), e uma bolsa para o coordenador do projeto, que deve ser professor do Departamento de História. ${ }^{6}$ No ano de 2014, iniciou-se o segundo projeto institucional na Udesc, com onze cursos envolvidos. O subprojeto da história passou a ter doze bolsas para acadêmicos que, devido aos cortes feitos pelo governo ao final de 2015, foram reduzidas para dez bolsas, e duas bolsas para professor/a supervisor.

O trabalho realizado no Pibid História é organizado de modo a promover uma integração com a proposta de formação docente já desenvolvida no curso da Udesc. Tal proposta procura articular ensino e pesquisa, a partir do projeto intitulado "O pensamento histórico de crianças e adolescentes e o ensino de História na Educação Básica”, desenvolvido no Departamento de História desde 2008 e atualmente em sua terceira versão. É importante dizer que a primeira versão desse projeto integrou atividades de extensão, pesquisa e ensino, apoiada pelo programa Prodocência/Capes sendo que dele participaram acadêmicos do curso de História e professores da Educação Básica. Tanto nessa primeira experiência de 2008 quanto nas versões seguintes do projeto, o objetivo tem sido articular o exercício da docência em História às atividades de ensino e pesquisa na Educação Básica para que os acadêmicos, professores em formação inicial, tenham uma visão mais abrangente do processo de ensino. Para que isso se efetive, são realizadas diferentes atividades em escolas da rede pública de Florianópolis, acompanhadas pelas professoras orientadoras da Udesc e pelos supervisores e supervisoras das escolas.

O projeto Pibid possibilita uma experiência que é distinta daquela de simples observador, mas também é distinta daquela que o professor desenvolve no decorrer de sua trajetória profissional. A/O bolsista, ao mesmo tempo que ainda não tem as obrigações de regente da turma, também não é um simples observador da aula do/a professor/a, já que desenvolve atividades que o levam a vivenciar várias situações: de observador, de monitor e de responsável pelas atividades docentes. Ela/e acompanha as aulas do professor/a supervisor/a da escola e é convocado a desenvolver diferentes tarefas, tais como: orientar os alunos nas atividades em sala de aula, preparar material didático, corrigir 
trabalhos e provas, realizar oficinas para diferentes turmas e de diferentes conteúdos, redigir textos para a divulgação das atividades bem como artigos científicos nos quais é analisado o aprendizado dos estudantes a partir das atividades propostas (Rossato; Oliveira, 2015).

GÊNERO: POSSIBILIDADES E RESISTÊNCIAS NA INICIAÇÃO À DOCÊNCIA

A partir dessas práticas e proposições, os acadêmicos e acadêmicas, supervisionados pelos/as professores/as participantes do projeto, elaboram atividades condizentes com as demandas da unidade escolar onde estão inseridos. Tais demandas referem-se tanto aos elementos da cultura escolar quanto às lacunas curriculares ou mesmo às necessidades institucionalizadas a partir de políticas públicas para a educação. Nesse sentido, foram vários os temas abordados desde o início do projeto na Udesc, em 2011. Dentre temáticas diversas e incontornáveis, como o estudo de história da África e história indígena, e inúmeras questões metodológicas, como os debates sobre o uso de fontes na sala de aula, as questões de gênero mostraram-se recorrentes. Emergiram, ao longo desses anos, não apenas como conteúdo a ser abordado, mas também como elemento presente e bastante definidor nas mais diversas relações estabelecidas no espaço escolar.

Apesar da recorrência, nem sempre estudantes e supervisores sentiam-se confortáveis na abordagem de questões relacionadas a gênero e diversidade sexual. Na tentativa de compreender certa resistência ou desconforto, destacamos como explicações possíveis alguns hiatos epistemológicos na formação dos supervisores e a própria estrutura dos cursos de licenciatura, nos quais as questões de gênero aparecem apenas como transversais ou, quando muito, em disciplinas optativas (Silva, Rossato, Oliveira, 2013).

É preciso demarcar, nesse ponto, que os estudos de gênero constituem-se como um campo. As categorias por ele abarcadas, tais como "mulher", "mulheres", "relações de gênero", "identidades de gênero", "feminilidades", “masculinidades", e mesmo "feminismo" são objetos de constantes disputas em torno de seus sentidos e apropriação. O termo "gênero" não possui uma definição única, homogênea e consensual. É, aliás, algumas vezes acusado de possibilitar a desmobilização de causas políticas relacionadas aos movimentos feministas. ${ }^{7}$ Daí, talvez, possamos compreender algumas das dificuldades e 
inseguranças a respeito de sua utilização no ambiente escolar. Mesmo cientes desses debates contemporâneos, nossa reflexão aqui ampara-se na defesa da potencialidade da percepção de gênero como uma "categoria útil de análise histórica", conforme apregoado por Joan Scott (1990, p.14), ao afirmar que o gênero é "um elemento constitutivo de relações sociais fundadas sobre as diferenças percebidas entre os sexos e o gênero é um primeiro modo de dar significado às relações de poder”. Ainda que o texto e a proposição sejam amplamente utilizados, a possibilidade de se pensar as diferenças (sexuais e de gênero) como produções históricas, e, dessa forma, a própria história como narrativa constitutiva e (des)legitimadora dos gêneros é, ainda, desafiadora e bastante profícua.

As relações de gênero são intrínsecas ao espaço escolar na medida em que, desde sua institucionalização, a escola, através de mecanismos de hierarquização e ordenamento, produz diferenças. Tais diferenças, e particularmente aquelas que tratam da constituição de identidades de gênero, são produzidas tanto através de discursos implícitos sobre o que seriam competências e propensões características de homens e mulheres, quanto de práticas explícitas, como pode-se observar em aulas de Educação Física, onde meninos e meninas são, muitas vezes, destinados a atividades e espaços distintos.

Ainda que as identidades sociais não sejam resultado exclusivo da passagem pela instituição escolar, é necessário reconhecer, conforme aponta Guacira Lopes Louro, "que suas proposições, suas imposições e proibições fazem sentido, têm 'efeitos de verdade', constituem parte significativa das histórias pessoais" (Louro, 2007, p.21) A atenção a essas questões, somadas às percepções particulares de professores supervisores, motivaram a realização de oficinas pelos alunos e alunas envolvidos com o projeto. A elaboração das oficinas ancora-se nas proposições apresentadas por Isabel Barca (2004, p.134), ao demarcar que o estudo escolar da história caracteriza-se por uma "compreensão contextualizada do passado, com base na evidência disponível e pelo desenvolvimento de uma orientação temporal que se traduz na interiorização de relações entre o passado compreendido, o presente problematizado e o futuro perspectivado". As propostas de estudo organizadas, ainda que diferentes em relação aos recortes temporais, deveriam primar pela análise de fontes e por atividades que promovessem uma percepção não homogênea a respeito do 
passado. Tal percepção seria, então, o ponto de partida para uma problematização substanciada e responsável do presente.

Os recortes temporais escolhidos pelos alunos e alunas, em acordo com seus respectivos supervisores, e que serão trabalhados a seguir, foram "o Egito Antigo" e a "Era Vargas". Ambos porque possibilitariam percepções controversas a respeito das questões de gênero e, especialmente, dos lugares atribuídos à mulher. Vale pontuar que é bastante perceptível, mesmo no ambiente universitário, um atrelamento das questões de gênero à reflexão específica sobre condição feminina. A percepção e problematização das masculinidades como historicamente constituídas são ainda bastante incipientes e foram pouco referendadas durante a fase de planejamento das atividades.

As primeiras atividades foram realizadas no segundo semestre de 2014. Os acadêmicos do curso de História, I. J. e N. G., ministraram, para alunos do primeiro ano de ensino médio na Escola Estadual José Simão Hess, em Florianópolis (SC), oficina sobre a condição da mulher no Egito Antigo e no Egito Contemporâneo. Comumente, a abordagem do Egito em sala de aula refere-se ao espaço como um dos "berços da civilização", obliterando a óbvia constatação de pertencimento ao continente africano. Além disso, ressaltam-se as estruturas de organização e destacam-se alguns personagens (faraós) considerados fundamentais no sentido de explicar aspectos políticos particulares. A referência às mulheres, quando muito, limita-se à imagem de uma Cleópatra bela, sedutora e sagaz. De acordo com os acadêmicos bolsistas, um dos objetivos principais da atividade foi a tentativa de romper com a narrativa oficial de uma história masculina, na qual as mulheres ocupariam um capítulo à parte e sua presença seria não mais que um mero adereço ou uma informação complementar. ${ }^{8}$ Para tanto, iniciaram solicitando que os alunos expusessem palavras que remetessem à ideia prévia que possuíam sobre o tema "Egito". Quando haviam registrado várias palavras no quadro, começaram a indagar sobre a possibilidade de se pensar nas relações entre aquelas palavras e a participação das mulheres. Tal percepção é bastante oportuna, na medida em que um dos desafios do ensino escolar de história é a possibilidade de promover o desenvolvimento de formas particulares de se pensar as relações sociais e as relações de poder. No caso da atividade proposta, os alunos incitaram a reflexão sobre o quão masculinas são nossas referências a respeito do passado e, portanto, sobre a necessidade de questioná-las. Tal assertiva vem ao encontro de 
reflexões sobre o ensino de história segundo as quais é preciso, não privilegiar um conjunto específico de conhecimentos considerados socialmente válidos, mas estimular o desenvolvimento de um pensamento histórico (Bergmann, 1990). Esse, por sua vez, possibilitará romper com percepções calcificadas e essencialistas acerca de inúmeras questões, dentre as quais aquelas relativas a gênero e diversidade sexual.

Além disso, é necessário reconhecer que os conteúdos escolares que fazem parte de currículos e livros didáticos são selecionados e, portanto, trazem consigo intencionalidades políticas e sociais. No que diz respeito ao Egito Antigo, as referências são quase que exclusivamente os livros didáticos. Sendo assim, propor atividades e reflexões concentradas na participação de sujeitos pouco visibilizados em narrativas oficiais é uma forma de ampliar as percepções a respeito do passado e, concomitantemente, possibilitar o entendimento da historicidade constitutiva das relações sociais. Diversos trabalhos têm trazido à tona a discussão sobre o silêncio acerca das mulheres nos materiais didáticos. Nesse sentido, é interessante constatar que as observações realizadas por Vanderlei Machado e Reinaldo L. Lohn em 2004 persistem, apresentando poucas alterações nos tempos hodiernos. Ao analisarem a presença de ilustrações ou figuras femininas nos livros didáticos avaliados pelo Programa Nacional do Livro Didático (PNLD) em 1999, especificamente a respeito do Brasil colonial, os autores indicam que, apesar da presença de imagens, elas retratam as mulheres segundo uma lógica de complemento, na qual as mulheres figuram como apêndice ou grupo social alheio ao efetivo desenvolvimento da trama histórica. A presença de imagens, ou textos complementares, não significa, necessariamente, a incorporação das problemáticas de gênero no discurso histórico (Machado; Lohn, 2004). Percepção similar é apresentada por Letícia Mistura e Flávia Caimi, em um estudo longitudinal sobre relações de gênero e livros escolares. Para tanto, analisam edições publicadas entre 1910 e 2010, uma por década. E atestam, através da análise, a parca representação do gênero feminino nas obras. Particularmente nas décadas de 1990, 2000 e 2010, ressaltam que mesmo observando a incorporação de mais figuras femininas aos conteúdos, elas ainda figuram em bordas e margens, sendo ressaltadas em ocorrências pontuais sem grandes impactos no processo histórico (Mistura; Caimi, 2015). 
Perante tamanhas ausências institucionais, os acadêmicos bolsistas consideraram, ao fim da atividade, que seus objetivos haviam sido parcialmente atingidos, na medida em que conseguiram promover uma reflexão sobre a condição feminina pautada pelas relações entre passado e presente. Isso foi possível porque os bolsistas priorizaram nessa oficina a discussão sobre as inúmeras representações de Cleópatra, bem como sua subordinação às figuras masculinas que esvazia seu poder político na sociedade egípcia. Na segunda parte da atividade privilegiaram a discussão sobre a participação das mulheres nas manifestações que estavam ocorrendo - conhecidas como "Primavera Árabe" -, bem como sobre suas pautas de reivindicação, distintas das elaboradas por manifestantes homens, e ainda sobre as dificuldades enfrentadas por elas.

Tais relações voltaram à tona no segundo semestre de 2015, quando seis bolsistas atuaram, com três turmas de $9^{\text {os }}$ anos do Ensino Fundamental, também na Escola de Educação Básica Simão José Hess. A proposição inicial era construir trajetórias panorâmicas sobre a história das mulheres, da Era Vargas até os tempos atuais. As oficinas foram organizadas para serem desenvolvidas em seis aulas (duas aulas por semana) e envolviam uma parte expositiva-dialogada com uso do data show, a análise de documentos e a elaboração de texto narrativo sobre o tema por parte dos/as alunos/as. A partir dessa estrutura básica, os bolsistas, sob orientação de suas professoras e supervisora, redirecionaram a proposta para as demandas particulares dos grupos com os quais atuavam.

Nesse sentido, o recorte selecionado pelos acadêmicos I. L. e T. F. foi o da luta pelo direito ao voto e o das representações das mulheres em mídias diversas. Para tanto, organizaram as atividades em três momentos: análise de texto, análise de imagens publicitárias e exercício de produção textual. Os três momentos foram subsidiados pelas discussões já realizadas, em conjunto com a prof ${ }^{\text {a }}$ supervisora, sobre o contexto da Era Vargas no Brasil. Para a análise de texto, foi selecionado um artigo publicado em 1939, no Jornal das Moças, de título: "Tipos de mulheres fascinantes". Esse artigo determinava a presença de dois tipos de mulheres na sociedade brasileira da época: as "mulheres para casar" e as "mulheres para não casar". A constatação de que o elemento de qualificação das mulheres era sua aptidão para acompanhar ou não um homem causou, conforme pode-se imaginar, uma discussão bastante intensa. Ao longo dessa discussão, segundo o relato dos acadêmicos bolsistas, um dos pontos 
mais significativos foi o fato de que o envolvimento das meninas revelou-se predominantemente maior que o dos meninos. Elas expuseram sua discordância em exemplos de relações cotidianas, enquanto eles, aparentemente, não se sentiram motivados a participar, ficando calados durante o debate.

Tal percepção acerca do envolvimento (ou sua ausência) por parte dos alunos e alunas repetiu-se, em certa medida, na atividade seguinte. Ao apresentarem peças publicitárias de época e atuais, as quais retratavam mulheres nas mais inusitadas situações, a discussão foi novamente norteada pelas meninas da turma. A diferença com relação à primeira atividade é que o silêncio do primeiro momento foi alternado com exclamações de cunho sexista como: "o homem sabe dirigir melhor que a mulher" ou "o que é bonito é para ser mostrado". Essas manifestações já haviam sido identificados pela professora supervisora e discutidas ao longo das reuniões de planejamento.

As concepções dos/as estudantes sobre os papéis sociais, sobre o que é esperado de cada um, se constituem nas inúmeras experiências e relações que são estabelecidas fora do espaço escolar e se manifestam nos debates que ocorrem em sala de aula. Diante delas, os bolsistas assumem a grande dificuldade em lidar tanto com os conhecimentos prévios trazidos pelos alunos, quanto com esses elementos de uma experiência cotidiana que acabam por se impor ao espaço da sala de aula. Ressaltam a necessidade de identificar e saber lidar com as referências cotidianas dos estudantes, que pululam durante as aulas, e não somente com as narrativas historiográficas do passado. Indicam que as concepções e visões de mundo dos alunos e alunas são fundamentais para definir o objeto e a forma através da qual determinados temas históricos devem ser trabalhados em sala de aula. Preconceitos, entre os quais os de gênero, reproduzem violências e limitam as possibilidades de futuro, tanto para as alunas, quanto para os alunos, uma vez que definem o que é próprio e/ou esperado para as mulheres e para os homens. A grande dificuldade, nesse sentido, é propiciar uma abordagem dos conteúdos históricos que possibilite a reflexão e a necessidade de posicionamentos diferentes diante do presente.

A percepção de uma disparidade no que se refere à participação dos alunos e alunas nas discussões suscitadas pela atividade está presente também nas observações dos acadêmicos E. M. e G. R. A partir de materiais similares, optaram porém por promover debates mais circunscritos às questões sobre as lutas políticas das mulheres. Além das peças publicitárias e do artigo publicado 
no Jornal das Moças, os bolsistas apresentaram também o Código Eleitoral de 1932 e um material audiovisual, buscando direcionar a atenção dos alunos e alunas para o exame daquilo que classificaram como conquistas concretas das mulheres. Como o movimento sufragista fora protagonizado majoritariamente por mulheres brancas, os acadêmicos buscaram romper com uma narrativa excludente, apresentando casos como o de Antonieta de Barros, negra, primeira mulher a ocupar uma cadeira no Legislativo catarinense em 1937.

Apesar da diversificação dos materiais trabalhados, os acadêmicos relataram que, iniciado o debate, mesmo que todos e todas tenham lido os mesmos textos e observado as mesmas imagens, a participação das alunas foi destacada. Segundo os acadêmicos:

Todos os alunos leram o material, porém, quando abrimos ao debate e à projeção de ideias, majoritariamente as meninas da sala participaram da discussão. Os meninos em sua maioria ficaram quietos, se manifestaram somente quando solicitado por nós bolsistas. Notamos um relativo desprezo por parte dos alunos, uma repulsa em refletir sobre o papel das mulheres e suas conquistas. As conversas paralelas foram frequentes durante essa primeira etapa da oficina. ${ }^{9}$

A segunda parte da atividade desenvolvida pelos acadêmicos bolsistas destinou-se à análise de padrões de beleza a partir de peças publicitárias de época e atuais. Novamente, o silêncio dos meninos tornou-se evidente sendo que o único a manifestar-se trouxe à tona opiniões bastante generalistas e preconceituosas, afirmando que "aquele tipo de mulher gosta é de dinheiro".

A terceira dupla de bolsistas que ministrou essa mesma proposta com uma outra turma, igualmente de $9^{\circ}$ ano e também na Escola Estadual Simão Hess, deparou com situações próximas a essa última referendada. Segundo o relato dos bolsistas L. C. e L. W., após a leitura do artigo de 1939 e a identificação de diferentes estereótipos, considerados depreciativos para as mulheres à época, os alunos e alunas comentaram a questão apresentando comentários igualmente estereotipados e generalistas, como, por exemplo, "algumas alunas se expressaram dizendo que existem mulheres que querem 'se aparecer' mais do que as outras". ${ }^{10}$ Apesar dessas percepções, nessa turma em particular, os bolsistas ressaltaram um interesse peculiar, por parte dos alunos e alunas, pelas questões sociais, ao perceberem a ausência de referências às mulheres negras e indígenas nas peças publicitárias apresentadas. A interpretação dos bolsistas 
aloca esse interesse como resultante da proliferação de informações concernentes às questões feministas.

Segundo os bolsistas

muitos relatos de experiências foram compartilhados; é perceptível nos discursos dos/as adolescentes que a questão feminista tem se ampliado, e isso também se deve à grande difusão de informações que temos atualmente. É evidente que há muito a ser discutido, pois ainda predomina nos discursos dos/as alunos/as muitos preconceitos, o que é compreensível, visto que todos/as estão (estamos) inseridos na lógica patriarcal. ${ }^{11}$

Em uma tentativa de compreender o silêncio recorrente dos meninos da turma, alguns acadêmicos avaliaram que o tema "história das mulheres" não tem boa aceitação, sendo visto "de forma desqualificadora pela rede de sociabilidades na qual os mesmos estão inseridos dentro da escola" ${ }^{12}$ Curioso notar, porém, que mesmo enquanto tais impressões eram socializadas entre o grupo de bolsistas, as acadêmicas faziam uso da palavra de forma bastante enfática enquanto os acadêmicos pareciam reproduzir, em certa medida, o silêncio de seus alunos. A percepção dessa reação trouxe à tona diferentes reflexões, dentre as quais destacamos a confissão, por parte de alguns dos acadêmicos homens, de que pouco conseguem perceber o quanto as questões de gênero haviam sido determinantes ao longo de suas trajetórias escolares pessoais. No caso das acadêmicas mulheres, tais percepções eram bastante objetivas e se referiam não apenas à ausência de representatividade nos conteúdos e materiais didáticos, mas especialmente às exigências e imposições acerca do que era ou não apropriado a uma menina.

A partir desse desafiador exercício interpretativo e das dificuldades enfrentadas pelos bolsistas durante o desenvolvimento de suas atividades, podemos inferir, no mínimo, duas reflexões: a importância de uma formação docente inicial que transcenda o corpo de disciplinas teóricas e possibilite o desenvolvimento de competências que não são específicas de uma disciplina particular - na medida em que, como professores, lidamos não apenas com questões intrínsecas ao nosso campo de formação - e a legitimidade das questões de gênero como fundamentais para o conhecimento histórico.

No que diz respeito ao primeiro ponto, Maurice Tardif afirma que o docente se forma a partir de distintas experiências e aciona, em seu trabalho como 
professor, diferentes conhecimentos. Como podemos, porém, nos cursos de formação, propiciar essas novas experiências aos nossos acadêmicos? Como fazer com que as aulas de História se tornem um espaço onde seja possível ampliar a experiência da alteridade, o aprendizado de outras formas de ver e viver no mundo? Essa reflexão não serve somente para que os futuros professores desenvolvam estratégias para lidar com as desigualdades de gênero, mas também para as desigualdades étnicas, sociais, religiosas, regionais.

Tais questões incitam-nos a pensar o percurso de formação docente tomando por base as preleções de Jorge Larrosa sobre a noção de experiência. Ao apresentá-la como "o que nos passa, o que nos acontece, o que nos toca. Não o que se passa, não o que acontece, ou o que toca” (Larrosa, 2016, p.18), ele, não apenas nos possibilita pensar a educação a partir de posicionamentos críticos e/ou científicos, mas traz à tona a reflexão sobre a atribuição de sentidos àquilo que é experienciado. Constatamos, por meio dos relatos produzidos pelos bolsistas a respeito de suas dificuldades em lidar com questões polêmicas e cotidianas em sala de aula (como as manifestações preconceituosas e sexistas observadas durante as atividades) que, certamente, o conhecimento historiográfico, por mais fundamental e consistente que seja, não é suficiente para garantir o estabelecimento de uma relação efetivamente pedagógica. Esses momentos foram relatados com muitas ressalvas e um certo sentimento de impotência por parte dos bolsistas, quando percebiam-se diante de uma situação com a qual não sabiam lidar.

É importante considerar que a formação de professores demanda uma série de saberes outros, os quais, muitas vezes, não são aprendidos nos bancos universitários e, nesse sentido, a noção de experiência auxilia-nos a dimensionar a potencialidade educativa daquilo que é efetivamente experienciado. Tal potencialidade exige, porém, uma determinada postura ética, um modo particular de conduzir-se, de expor-se, uma vez que o saber de experiência é "um saber particular, subjetivo, relativo, contingente, pessoal” (Larrosa, 2016, p.32). Isso implica assumir que, no que diz respeito ao processo de formação docente, existem saberes que não se aprendem por vias técnicas ou teóricas. A iminência de uma situação em sala de aula para a qual não se está previamente preparado tem, em si, um potencial formativo. É preciso, porém, assumi-lo como tal. O inusitado, o inesperado, o imprevisto fazem parte do cotidiano escolar. É a predisposição ética do docente perante tais situações que possibilitará, ou não, 
a constituição de saberes a partir do que é experienciado. A formação docente, além do caráter científico e didático/metodológico, deve atentar igualmente à experiência, ou melhor, à possibilidade de se aprender com ela.

No que se refere às questões de gênero, é necessário lembrar que sua incorporação curricular é bastante recente. Quando observamos os Parâmetros Curriculares Nacionais, um dos temas transversais prescritos é "orientação sexual" sendo a expressão 'relações de gênero' definida como "conjunto de representações sociais e culturais construídas a partir da diferença biológica dos sexos" (PCN/Orientação Sexual, 1998, p.296). Encontramos também que no conceito de gênero toma-se o desenvolvimento das noções de 'feminino' e 'masculino' como “construção social” (PCN/Orientação Sexual, 1998, p.321). Para a área de Ciências Humanas e suas Tecnologias, no item "o que e como estudar História?" encontramos a referência textual às "problemáticas e anseios individuais, de classe, de gêneros, de grupos sociais, locais, regionais, nacionais e mundiais" como elementos incorporados ao conceito de cidadania, o qual é caro não apenas à História, mas perpassa todas as disciplinas (PCN/História, 1998, p.24). Ainda que previstas nos parâmetros curriculares desde 1998, a prescrição, sabe-se, não é garantia efetiva de abordagens consistentes e comprometidas com o que tem sido produzido, em termos teóricos e empíricos, nesse campo em específico. A incorporação das questões de gênero nos currículos de História, ainda que possamos observar um grande esforço nesse sentido, é bastante incipiente.

Eis a relevância de se insistir, portanto, nas reflexões concernentes à categoria gênero e à necessidade de reconhecê-la como constitutiva - e não como um adendo - ao conhecimento histórico. Os livros didáticos ressaltados anteriormente configuram-se, nesse sentido, como um exemplo bastante oportuno. Conforme o levantamento realizado por Mistura e Caimi, ainda que possamos observar uma incorporação de figuras femininas aos conteúdos históricos nas três últimas décadas, esse avanço diz respeito, majoritariamente, às mulheres ícones para movimentos artísticos, como Anita Malfatti. Ou a grupos cuja participação na esfera pública é considerada relevante, ainda que representada de forma bastante generalizada, como o caso dos movimentos sufragistas (Mistura; Caimi, 2015).

Além das questões concernentes à formação dos professores e professoras que atuam nas redes particulares e públicas da educação básica (muitos, 
sabemos, não tiveram contato efetivo com as discussões de gênero ao longo de suas respectivas graduações), não podemos desconsiderar os esforços políticos para que tais questões não sejam efetivamente abordadas no espaço escolar. Tais esforços vêm ganhando força e se tornaram bastante evidentes em 2015 com a ascensão dos debates a respeito da equivocada noção de "ideologia de gênero"13 e da submissão de projetos de lei amparados pelo ideário do programa "Escola sem partido", sendo que um deles, inclusive, chegou à consulta pública, conforme citado no início deste artigo.

Ainda que o conhecimento histórico escolar e o conhecimento histórico acadêmico sejam de ordens distintas, reconhecemos que, especialmente no que diz respeito aos debates em torno das questões de gênero, existe uma visível disparidade em termos qualitativos. De acordo com Joana Maria Pedro (2011, p.270), na reflexão sobre os usos das relações de gênero como categoria da historiografia contemporânea, "é crescente o número de pessoas que incorporam em suas análises as diferenças de gênero para observar os impactos dos acontecimentos sobre homens e mulheres". Se no campo acadêmico as relações de gênero são reconhecidas como uma categoria de análise ${ }^{14}$ válida, no campo escolar observamos um movimento ainda bastante tímido.

As referências a algumas mulheres em caixas explicativas, nas margens dos textos principais, apresentam comumente trajetórias consideradas extraordinárias. Vale ressaltar que a ideia do extraordinário, para os termos desta reflexão, é bastante profícua na medida em que, ao mesmo tempo que pode se referir a personagens ou feitos singulares, ratifica que essas personagens ou esses mesmos feitos escapam a uma ordem preestabelecida. Dessa forma, as mulheres ganham menção na narrativa histórica apenas quando suas ações fogem a uma ordem que predetermina os lugares sociais de gênero e, assim, interferem na esfera pública. Sendo que, considerada legítima como objeto de estudo da história, a esfera pública é, de antemão, majoritariamente masculina. A invisibilidade das mulheres na narrativa histórica estaria assim estreitamente vinculada àquilo que é considerado como conhecimento histórico escolar válido. 


\section{CONSIDERAÇÕES FINAIS}

Uma rápida observação de livros didáticos recentes, ou mesmo de textos publicados como proposições para compor a Base Nacional Comum Curricular, permite constatar que, apesar das inúmeras preocupações metodológicas e dos debates advindos de reivindicações dos movimentos sociais (especialmente no que diz respeito a história dos povos indígenas e história da África, dos africanos e afrodescendentes), os eventos selecionados como constitutivos daquilo que deve ser considerado conhecimento histórico escolar são marcadamente os protagonizados por homens, ou antes, aqueles cujas narrativas insistem em ressaltar apenas a dimensão pública, oficial e masculina dos eventos.

A reiteração de uma história com as características descritas auxilia-nos a entender o desconforto e certo desinteresse por parte de alguns alunos e alunas, na medida em que tratar de história das mulheres ou pensar a história a partir das relações de gênero significaria assim tratar de questões "acessórias" ao conhecimento histórico e, portanto, menos importantes. Faz-se necessário, nesse sentido, não apenas a incorporação de narrativas protagonizadas por mulheres aos textos e programas da disciplina escolar História. Ainda que tal iniciativa represente um avanço significativo com relação às formas de se pensar o passado, ela não é suficiente. É preciso agregar efetivamente à narrativa escolar noções menos fixas a respeito do público e do privado. Noções que possibilitem efetivamente a percepção de que a história não é uma narrativa uníssona, homogênea e cristalizada. Noções a partir das quais homens, mulheres e outras identificações identitárias possam reconhecer diferentes possibilidades de atuação, igualmente relevantes para a conformação daquilo que se considera história. É preciso, finalmente, questionar os elementos constitutivos e de validação daquilo que tem sido considerado como legítimo para o estudo escolar da história.

\section{REFERÊNCIAS}

BARCA, Isabel. Aula Oficina: do projecto à avaliação. In: (Org.) JORNA-

DAS INTERNACIONAIS DE EDUCAÇÃO HISTÓRICA: Para uma educação histórica com qualidade, 4., 2004, Braga. Actas... Braga: Centro de Estudos em Educação e Psicologia, Universidade do Minho, 2004. p.131-144. 
BERGMANN, Klaus. A história na reflexão didática. Revista Brasileira de História, v.9, n.19, p.29-42, set. 1989/fev. 1990. Disponível em: file:///C:/Users/Usuario/Downloads/klausbergmann\%20(1).pdf; Acesso em: 25 abr. 2005.

DOSSE, François. História do Tempo Presente e Historiografia. Tempo e Argumento, Florianópolis, v.4, n.1, p.5-22, jan./jun. 2012. Disponível em: http://revistas.udesc. br/index.php/tempo/article/view/2175180304012012005; Acesso em: 20 out. 2016.

FURLANI, Jimena. "Ideologia de Gênero"? Explicando as confusões teóricas presentes na cartilha. (rev. 2016). Florianópolis: Faed, Udesc. Laboratório de Estudos de Gênero e Família. 2015. Disponível em: https://www.facebook.com/jimena.furlani; Acesso em: 20 mar. 2016.

LARROSA, Jorge. Notas sobre a experiência e o saber de experiência. In: Tremores: escritos sobre experiência. Belo Horizonte: Autêntica, 2016.

LOURO, Guacira L. O corpo educado: pedagogias da sexualidade. Belo Horizonte: Autêntica, 2007.

MACHADO, Vanderlei; LOHN, Reinaldo L. Gênero e imagem: relações de gênero através das imagens dos livros didáticos de história. Gênero, Niterói, v.4, n.2, p.119-124, 2004. Disponível em: http://www.revistagenero.uff.br/index.php/revistagenero/article/view/249/169; Acesso em: 10 set. 2016.

MISTURA, Letícia; CAIMI, Flávia E. O (não) lugar da mulher no livro didático de história: um estudo longitudinal sobre relações de gênero e livros escolares (19102010). Aedos, Porto Alegre, v.7, n.16, p.229-246, 2015. Disponível em: http://seer. ufrgs.br/index.php/aedos/article/view/57019; Acesso em: 15 set. 2016.

PEDRO, Joana M. Relações de gênero como categoria transversal na historiografia contemporânea. Topoi, v.12, n.22, p.270-283, jan./jun. 2011. Disponível em: http://www.scielo.br/pdf/topoi/v12n22/1518-3319-topoi-12-22-00270.pdf; Acesso em: 20 out. 2016.

ROSSATO, Luciana; OLIVEIRA, Nucia A. S. de. Tornar-se professor de história: a experiência como bolsista Pibid. In: MARTINS, Rosa E. M. W.; ROSSATO, Luciana (Org.) Reflexões sobre as experiências do Pibid na Udesc. Santa Cruz do Sul: Ed. Unisc, 2015. p.57-72.

SCOTT, Joan. Gênero, uma categoria útil de análise histórica. Educação e Realidade, Porto Alegre, v.16, n.2, p.5-22, jul./dez. 1990.

SILVA, Cristiani B. da; ROSSATO, Luciana; OLIVEIRA, Nucia A. S. de. A formação docente: igualdade de gênero e diversidade. Revista Retratos da Escola, Brasília, v.7, n.13, p.453-465, jul./dez. 2013. Disponível em: http://www.esforce.org.br/index.php/semestral/article/view/318/488; Acesso em: 5 abr. 2014.

TARDIF, Maurice. Saberes docentes e formação profissional. Petrópolis: Vozes, 2002. 
TARDIF, Maurice. Saberes profissionais dos professores e conhecimentos universitários: elementos para uma epistemologia da prática profissional dos professores e suas consequências em relação à formação para o magistério. Revista Brasileira de Educação, Rio de Janeiro: Anped, n.13, p.5-24, jan./abr. 2000. Disponível em: http://anped.tempsite.ws/novo_portal/rbe/rbedigital/RBDE13/RBDE13_05_MAURICE_TARDIF.pdf; Acesso em: 16 maio 2009.

\section{NOTAS}

${ }^{1}$ Projeto inclui entre as diretrizes e bases da educação nacional, de que trata a Lei no 9.394 , de 20 de dezembro de 1996, o "Programa Escola sem Partido". No dia 14 ago. 2016 às 20:14 tinha 191.193 votos contra o projeto e 180.611 votos a favor. Disponível em: https://www12. senado.leg.br/ecidadania/visualizacaomateria?id=125666; Acesso em: 14 ago. 2016.

${ }^{2}$ Disponível em: http://basenacionalcomum.mec.gov.br.

${ }^{3}$ A cartilha anônima "Você já ouviu falar sobre a 'ideologia de gênero'?" é facilmente encontrada na internet. Em junho de 2015 foi disponibilizada em sítios eletrônicos de inúmeras igrejas e arquidioceses católicas. Para a elaboração dessas reflexões, utilizamos o link encontrado em: https://igrejansn.files.wordpress.com/2015/07/cartilha-ideologia-de-genero.pdf; Acesso em: 15 mar. 2016.

${ }^{4}$ Sobre as quatro oficinas ministradas, ver os relatos de experiências que estão disponíveis no blog do Pibid de História da Udesc em https://udescpibidhistoria.wordpress.com.

${ }^{5}$ Durante esses anos de projeto estiveram envolvidos quatro escolas (E. E. Padre Anchieta, E. M. Vitor Miguel de Souza, E. E. Simão José Hess, E. M. Henrique Veras) e quatro professores supervisores (Valéria Florentino, Marcos Francisco da Silva, Renata Mibielli e César Jungblut).

${ }^{6} \mathrm{~A}$ coordenação do subprojeto é dividida entre as professoras da área de Ensino de História: Caroline Jaques Cubas, Cristiani Bereta da Silva, Luciana Rossato, Núcia Alexandra de Oliveira.

${ }^{7}$ No artigo "Relações de gênero como categoria transversal na historiografia contemporânea", publicado em 2011, Joana Maria Pedro constrói um panorama bastante amplo acerca dos debates referentes aos estudos de gênero e das categorias por ele abarcadas. Trata também da apropriação dessas categorias na produção historiográfica contemporânea e, especialmente, no Cone Sul. Disponível em: http://www.scielo.br/pdf/topoi/v12n22/1518-3319-topoi-12-22-00270.pdf.

${ }^{8}$ Conforme mencionado anteriormente, os relatos dos alunos podem ser lidos integralmente no blog do Pibid de História da Udesc: https://udescpibidhistoria.wordpress.com.

9 Relatório de experiências. Disponível em https://udescpibidhistoria.wordpress. com/2015/11/27/historia-das-mulheres-da-era-vargas-a-atualidade-3/. 
${ }^{10}$ Cf. Relato de experiências. Disponível em: https://udescpibidhistoria.wordpress. com/2016/06/24/historia-das-mulheres-da-era-varga-a-atualidade/.

${ }^{11}$ Cf. Relato de experiências. Disponível em https://udescpibidhistoria.wordpress. com/2016/06/24/historia-das-mulheres-da-era-varga-a-atualidade/.

${ }^{12}$ Cf. Relato de experiências. Disponível em https://udescpibidhistoria.wordpress. com/2015/11/27/historia-das-mulheres-da-era-vargas-a-atualidade-3/.

${ }^{13}$ A respeito da noção de "ideologia de gênero", conferir o minucioso trabalho realizado por Jimena Furlani. Publicado em 2015, foi amplamente compartilhado nas redes sociais e disponibilizado em sítios de centros de estudos e laboratórios dedicados aos estudos de gênero.

${ }^{14}$ É preciso ressaltar que assumir o gênero como uma categoria de análise histórica não implica desconsiderar os debates políticos, enfrentamentos e diferentes/divergentes modos de apropriação e percepção dessa mesma categoria.

Artigo recebido em 10 de setembro de 2016. Aprovado em 24 de outubro de 2016. 